\title{
Do Anglo countries still form a values cluster? Evidence of the complexity of value change
}

\author{
Carolyn P. Egri a,1, Shaista E. Khilji ${ }^{\text {b,* }}$, David A. Ralston ${ }^{c, 2}$, Ian Palmer ${ }^{\text {d,3 }}$, Ilya Girson ${ }^{\text {e,4 }}$, \\ Laurie Milton $^{\mathrm{f}, 5}$, Malika Richards ${ }^{\text {g,6 }}$, Prem Ramburuth ${ }^{\text {h,7 }}$, Audra Mockaitis ${ }^{\mathrm{i}, 8}$ \\ a Simon Fraser University, 8888 University Drive, Burnaby, B.C. V5A 1S6, Canada \\ ${ }^{\mathrm{b}}$ The George Washington University, 2134 G Street, NW, Washington DC 20052, USA \\ ${ }^{\mathrm{c}}$ Department of Management and International Business College of Business Administration, Florida International University, 11200 SW 8 Street, n/a Miami, FL 33199, USA \\ ${ }^{\mathrm{d}}$ RMIT University, 300 Queen St, Melbourne VIC 3000, Australia \\ e University of Westminster, 35, Marylebone Road, London NW1 5LS, UK \\ ${ }^{\mathrm{f}}$ University of Calgary, 2500 University $\mathrm{Dr}, \mathrm{NW}$, Alberta, Canada \\ ${ }^{g}$ Pennsylvania State University - Berks, Tulpehocken Road, Reading, PA 19610, USA \\ ${ }^{\mathrm{h}}$ University of New South Wales, Sydney, NSW 2052, Australia \\ ${ }^{\mathrm{i}}$ Monash University, 27 Sir John Monash Drive, Caufield East, VIC 3145, Australia
}

\section{A R T I C L E I N F O}

\section{Keywords:}

Age

Anglo cluster

Cultural values

Gender

Life stage

\begin{abstract}
A B S T R A C T
To what extent does the Anglo Cluster remains a cultural cluster in today's managerial and professional workforce? Across six Anglo countries (Australia, Canada, New Zealand, South Africa, U.K., and U.S.), we found significant differences in values orientations (openness to change, conservation, self-enhancement, and self-transcendence values) that challenge the concept of a cohesive Anglo cluster. We also explored the influence of micro-level factors on values orientations and found consistent life-stage and gender differences across countries. We conclude that, even within a group of countries perceived as similar, multi-level analyses are needed to fully capture the essence of values differences across and within countries.
\end{abstract}

(c) 2011 Elsevier Inc. All rights reserved.

\section{Introduction}

The Anglo countries, primarily a product of British colonialism, are dispersed around the globe. Based on an analysis of research conducted over three decades (1960s to early 1980s), Ronen and Shenkar (1985) designated Australia, Canada, Ireland, New Zealand, South Africa, U.K., and the U.S. as a "cultural cluster.' Recent studies have also concluded that these countries constitute an Anglo cluster with variation regarding postapartheid South Africa. South Africa has been identified as part

\footnotetext{
* Corresponding author. Tel.: +1 202994 1146; fax: +1 2029944928.

E-mail addresses: egri@sfu.ca (C.P. Egri), sekhilji@gwu.edu (S.E. Khilji), ralstond@fiu.edu (D.A. Ralston), an.palmer@rmit.edu.au (I. Palmer), girsoni@westminster.ac.uk (I. Girson), laurie.milton@haskayne.ucalgary.ca (L. Milton), mur12@psu.edu (M. Richards), p.ramburuth@unsw.edu.au

(P. Ramburuth), audra.Mockaitis@vuw.ac.nz (A. Mockaitis).

1 Tel.: +1 778782 3456; fax: +1 7787825920 .

2 Tel.: +1 405321 9994; fax: +1 4053257688 .

3 Tel.: +61039925 1412; fax: +61 0399255624 .

4 Tel: +44 0207911 5000x3037; fax: +44 02079115703.

5 Tel.: +1 403220 8523; fax: +1 4032820095 .

6 Tel.: +61 0396 6000; fax: +61 03966026 .

7 Tel.: +61 29385 5846; fax: +6129385 5933 .

8 Tel.: +61 399032807; fax: +61 399054007 .
}

of an Africa cluster (e.g., Inglehart \& Welzel, 2005; Schwartz, 2006). The GLOBE study's ethnic segmentation approach identified that black South Africans belonged to an Africa cluster whereas the small minority of white South Africans remains in the Anglo cluster (Ashkanasay, Trevor-Roberts, \& Earnshaw, 2002).

A review of the macro-level characteristics across the Anglo countries indicates that with the exception of South Africa, this group of countries is substantially similar. Australia, Canada, New Zealand, U.K., and U.S. score high on democratization, economic development level, and technological sophistication (see Table 1). However, countries such as Germany and Japan could also fit into this typology of macro-level predictors. What has led to the clustering view for this group of Anglo countries can be summarized by the intersection in their histories. All were part of the historic British Empire, all are English-speaking, and all have Protestantism as their religious base (Smith \& Schwartz, 1997). While these commonalities have been the prime reason for the Anglo countries being designated a cluster, changes in country contexts due to an array of external influences emanating from global business practices (Steel \& Taras, 2010) raises the question: Are these countries still a cultural values cluster? An answer will provide a $21^{\text {st }}$ century conceptualization of the Anglo country relationships. 
Table 1

Comparison of the economic indicators of the Anglo countries in this study. ${ }^{a}$

\begin{tabular}{|c|c|c|c|c|c|c|}
\hline & Australia & Canada & New Zealand & South Africa & U.K. & U.S. \\
\hline GDP per capita (in US\$) & $\$ 26,485$ & $\$ 27,449$ & $\$ 34,121$ & $\$ 3622$ & $\$ 30,688$ & $\$ 37,685$ \\
\hline Unemployment rate & $6.4 \%$ & $7.6 \%$ & $4.1 \%$ & $\mathrm{~N} / \mathrm{A}$ & $5.2 \%$ & $5.8 \%$ \\
\hline Inflation rate & $3.0 \%$ & $2.3 \%$ & $3.1 \%$ & $9.2 \%$ & $1.3 \%$ & $1.6 \%$ \\
\hline Gender Gap Index score (rank) & $.7163(15)$ & $.7165(14)$ & $.7649(5)$ & $.7125(18)$ & $.7365(9)$ & $.7042(23)$ \\
\hline Polity & 10 & 10 & 10 & 9 & 10 & 10 \\
\hline \multicolumn{7}{|l|}{ Cultural values } \\
\hline Individualism & 90 & 80 & 79 & 65 & 89 & 91 \\
\hline Power distance & 36 & 39 & 22 & 49 & 35 & 40 \\
\hline Uncertainty avoidance & 51 & 48 & 49 & 49 & 35 & 46 \\
\hline Masculinity & 61 & 52 & 58 & 63 & 66 & 62 \\
\hline Traditional/secular-rational values & .21 & -.26 & .00 & -1.09 & .06 & -.81 \\
\hline Survival/self-expression values & 1.75 & 1.91 & 1.86 & -.10 & 1.68 & 1.76 \\
\hline
\end{tabular}

a Sources: Economic data from World Economic Outlook Database 2003 (http://www.imf.org/external/pubs/ft/weo/2008/01/weodata/); Gender Gap Index 2006 (http://

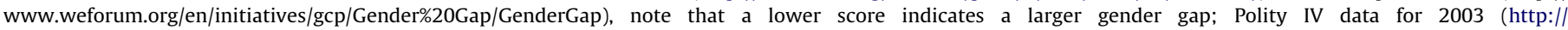

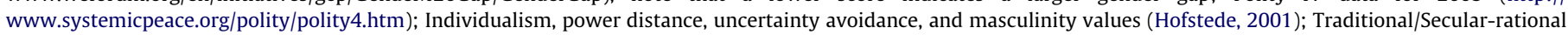
and Survival/Self-expression values (http://www.worldvaluessurvey.org).

Arguments that cross-cultural values similarities and differences are determined by both macro and micro factors (e.g., Au \& Cheung, 2004; Steel \& Taras, 2010) call for a more comprehensive investigation to include micro, as well as macro, influences on cultural values formation (Tung \& Verbeke, 2010). Previous research has highlighted the significance of micro-level factors, such as age and gender, in explaining values differences within and across societies (e.g., Ralston, Egri, Casado, Fu \& Wagenheim, 2009; Setterson \& Mayer, 1997; Steel \& Taras, 2010). At the individuallevel, age and gender are important influences on personal values orientations, whereas at the societal-level, these are common demographics by which institutions (e.g., family, educational, and occupational) are organized (LaFontaine, 1978). Accordingly, our second research question is: Does investigating micro-level factors provide additional insights regarding value orientations among the Anglo-cluster countries?

Our investigation of these two research questions offers new insights as well provide a more viable foundation for contemporary cross-cultural research (Steel \& Taras, 2010). In sum, this study's contributions to the international management literature are twofold. First, we provide current empirical evidence regarding values similarities and differences among the Anglo countries. Second, we determine whether micro-level influences on values orientations provide empirical evidence of similarities and/or differences across these countries. The remainder of this paper is organized as follows. First, the theoretical background of values measurement, cultural values of Anglo cluster countries, and the effect of micro-level variables are presented to formulate research hypotheses. We then present the research methodology followed by study results. We conclude with a discussion of findings, research limitations, and identify implications for future research.

\section{Theoretical background and formulation of hypotheses}

\subsection{Measuring values}

Much of earlier comparative analyses of cultural values have been conducted at the country level. Rokeach (1973) advocated the importance of capturing uniqueness of personal values and proposed that cultural values be measured at the individual level. Schwartz's (1994) integrative theory of values was an important step in the development of values theory, and his instrumentSchwartz Values Survey (SVS) is considered to be a rigorous measure of values at the individual-level (Sawyerr, Strauss, \& Yan, 2005). The SVS values model identifies a quasi-circumplex structure with four higher-order values: openness to change, conservation, self-enhancement, and self-transcendence (Schwartz, 1994). These four higher-order values dimensions are the dependent measures in our study.

\subsection{Anglo country values orientations}

Ronen and Shenkar (1985) identified language, religion, and geography as constituting the three primary drivers leading to the creation of a cluster. The six Anglo countries in our study share a common language (English) as well as religious and socio-political ideologies (Ronen \& Shenkar, 1985; Smith \& Schwartz, 1997). Further, they share comparable historical and political linkages. All were members of the British Empire (Ashkanasy, Trevor-Roberts, \& Earnshaw, 2002) and have high levels of political democratization (Marshall, Jaggers, \& Gurr, 2010). Unlike other country clusters that are characterized by geographic proximity, countries in the Anglocluster are geographically dispersed (except for neighboring Canada and the U.S.). While the Anglo countries clearly do not have a proximal geographic relationship, having a high level of colonial association for years and the subsequent enduring economic association may have served as a de facto "proximity" influence for these countries.

Previous research suggests that economic prosperity is associated with higher importance accorded to openness to change and selfenhancement values. In contrast, conservation and self-transcendence values have been found to be more important in poorer societies (House, Hanges, Javidan, Dorfman, \& Gupta, 2004; Inglehart, 1997; Inglehart \& Welzel, 2005; Wolf, 1966). As shown in Table 1, the U.S., Canada, U.K., New Zealand, and Australia have high economic development levels whereas South Africa has a medium economic development level. Thus, we propose:

H1. There are differences in values orientations of business managers and professionals across countries in the Anglo cluster.

H1a. Businesspersons in Australia, Canada, New Zealand, the U.K., and the U.S. attribute higher importance to openness to change values than those in South Africa.

H1b. Businesspersons in Australia, Canada, New Zealand, the U.K., and the U.S. attribute higher importance to self-enhancement values than those in South Africa.

H1c. Businesspersons in South Africa attribute higher importance to conservation values than those in Australia, Canada, New Zealand, the U.K., and the U.S. 
H1d. Businesspersons in South Africa attribute higher importance to self-transcendence values than those in Australia, Canada, New Zealand, the U.K., and the U.S.

\subsection{Individual factors influencing values orientations}

Despite an understanding that individual characteristics influence values and the nature of values evolution in a society, there has been a relative lack of cross-cultural research on the impact of micro-level factors on values orientations (Ralston, 2008). Previous research has identified age/life-stage and gender as important factors in the study of values (e.g., Lyons, Duxbury, \& Higgins, 2005; Steel \& Taras, 2010), with some scholars arguing that both age and gender operate interdependently (LaFontaine, 1978; Settersten \& Mayer, 1997).

\subsubsection{Age/life-stage}

Erikson's (1997) life-stage model presents a progression of human development over an individual's entire life that has often been used to develop meaningful comparisons across age groups. The life-stage model is psychosocial in nature and addresses personality, cognition, external environment, and relationships of the individual to postulate different life stages. Each life-stage is considered to be distinct in terms of its cognitive, emotional, and behavioral experiences and responses (Erikson, 1997; Ralston, Hallinger, Egri, \& Naothinsuhk, 2005). Of Erickson's life-stages, we focus on only early adulthood (20-39 years) and middle adulthood (40-59 years), which are the most relevant in terms of business careers in organizations.

Early adulthood is about experimenting and developing social and professional lives. A young adult develops patterns of cooperation and competition by building the capacity to love and commit to others for mutual satisfaction. Early adulthood is a period of high spontaneity, creativity, and energy. In contrast, middle adulthood is a period of personal mastery and assuming leadership in family and work. During middle adulthood, a person develops future education and training for others, and focuses on contributing to the greater good, building a legacy, and making a positive difference in one's sphere of influence (Levinson, 1997).

Recent research has shown evidence of converging values, especially among young adults (Khilji, 2004; Warner, 2004). Kwong (1994) also noted that individualism had been growing among the younger groups of Chinese, which is in sharp contrast with older Chinese who grew up in 'seclusion' under socialist regimes. Egri and Ralston's (2004) study supports these arguments and shows that American and Chinese youth have more similar values orientations than do Chinese youth and Chinese older workers. Further, our review of the values literature did not reveal any life-stage research that used the SVS to compare countries of the Anglo cluster. The present research adds to an understanding of Erikson's (1997) life-stage theory by examining values orientations across six Anglo countries.

To summarize, research has shown that younger individuals are more open to change (Davis, Chatterjee, \& Heuer, 2006; Khilji, 2004) and more achievement oriented (Lyons et al., 2005) than their older counterparts. Life-stage theory also suggests that early adulthood is a period of high energy, creativity, and desire for self/ social recognition and control (Levinson, 1997). Therefore, individuals in early adulthood should focus more on achievement of personal goals than would individuals in middle adulthood who are more concerned with contributing to the societal good (Erikson, 1997). Thus, we propose:

H2a. Early adulthood businesspersons attribute higher importance to openness to change values than do middle adulthood businesspersons.

H2b. Early adulthood businesspersons attribute higher importance to self-enhancement values than do middle adulthood businesspersons.

H2c. Middle adulthood businesspersons attribute higher importance to conservation values than do early adulthood businesspersons.

H2d. Middle adulthood businesspersons attribute higher importance to self-transcendence values than do early adulthood businesspersons.

\subsubsection{Gender}

Social structural origin theory provides the rationale for gender differences in personal values orientations. Specifically, genderbased differences are proposed to be the result of females' and males' adjustment to the different roles into which they are socialized (Eagly, 1995). Since most societies socialize females and males to play different roles, gender differences in values priorities

Table 2

Demographic characteristics of country samples $(N=1057)$.

\begin{tabular}{|c|c|c|c|c|c|c|}
\hline & Australia & Canada & New Zealand & South Africa & U.K. & U.S. \\
\hline$N$ & 153 & 256 & 91 & 132 & 237 & 188 \\
\hline Age: mean (s.d.) & $29.0(7.4)$ & $39.8(10.9)$ & $43.7(12.4)$ & $39.6(9.4)$ & $41.4(10.8)$ & $32.5(6.5)$ \\
\hline Male $(\%)$ & $65 \%$ & $58 \%$ & $50 \%$ & $67 \%$ & $50 \%$ & $65 \%$ \\
\hline Education level $^{\mathrm{a}}$ : mean (s.d.) & $3.8(.8)$ & $4.3(.7)$ & $3.9(.9)$ & $4.0(.7)$ & $4.1(.9)$ & $4.7(.5)$ \\
\hline \multicolumn{7}{|l|}{ Position level (\%) } \\
\hline Non-supervisory & $37 \%$ & $40 \%$ & $28 \%$ & $33 \%$ & $15 \%$ & $47 \%$ \\
\hline First- level manager & $26 \%$ & $27 \%$ & $21 \%$ & $16 \%$ & $15 \%$ & $25 \%$ \\
\hline Middle-level manager & $27 \%$ & $20 \%$ & $8 \%$ & $22 \%$ & $27 \%$ & $20 \%$ \\
\hline Upper-level manager & $10 \%$ & $13 \%$ & $43 \%$ & $29 \%$ & $43 \%$ & $8 \%$ \\
\hline \multicolumn{7}{|l|}{ Company size } \\
\hline Less than 100 employees & $32 \%$ & $28 \%$ & $49 \%$ & $21 \%$ & $18 \%$ & $17 \%$ \\
\hline 100-1000 employees & $24 \%$ & $36 \%$ & $21 \%$ & $30 \%$ & $40 \%$ & $22 \%$ \\
\hline More than 100 employees & $44 \%$ & $36 \%$ & $30 \%$ & $49 \%$ & $42 \%$ & $61 \%$ \\
\hline \multicolumn{7}{|l|}{ Industry (\%) } \\
\hline Manufacturing & $13 \%$ & $4 \%$ & $13 \%$ & $20 \%$ & $16 \%$ & $22 \%$ \\
\hline Resource-based & $2 \%$ & $3 \%$ & $3 \%$ & $2 \%$ & $2 \%$ & $1 \%$ \\
\hline Services & $34 \%$ & $31 \%$ & $45 \%$ & $31 \%$ & $19 \%$ & $45 \%$ \\
\hline Public sector & $20 \%$ & $26 \%$ & $36 \%$ & $33 \%$ & $23 \%$ & $27 \%$ \\
\hline Other & $31 \%$ & $36 \%$ & $2 \%$ & $14 \%$ & $40 \%$ & $6 \%$ \\
\hline
\end{tabular}

a Education level coded as follows: $1=4$ or fewer years completed, $2=5-8$ years, $3=9-12$ years, $4=$ undergraduate university, $5=$ Masters degree, $6=$ Doctorate degree . 
are likely to emerge (Lyons et al., 2005). Struch, Schwartz, and Kloot (2002, p. 18) argued that: "Because social experiences affect the associations that develop among values, the different rolebased experiences of men and women may yield differences in the meanings of some values." They further reason that a similar structure of distinct gender roles across societies may lead to consistent gender differences in values across cultures.

Gender differences in personality traits seem to be persistent across a diverse array of measures, data sources, ages, and cultures (Schmitt, 2008). For example, the NEO Personality Inventory conducted across 76 cultures revealed that females are warmer, more open to feelings, anxious, and aesthetic; whereas males are more assertive, excitement-seeking, and open to ideas (McCrae \& Terracciano, 2005). An interesting finding has been that gender differences are often greater in wealthier nations. Improved national wealth and gender equality results in larger value differences between males and females (Costa, Terraccino, \& McCrae, 2001; McCrae, 2002). Conversely, Schwartz and Rubel (2005) found that gender differences in self-direction values are smaller in richer and more individualistic countries than in poorer countries with more collectivistic cultures. Similarly, Steel and Taras' (2010) meta-analysis found that gender differences are indeed smaller in countries with higher gender equality.

While the notion of gender differences is widely accepted, recent research using the SVS has not shown consistent gender patterns (Lyons et al., 2005). For instance, Struch et al.'s (2002) study of gender differences across and within eight cultural regions found no noteworthy gender differences in values. They concluded that males and females construed the meaning of values similarly across and within various cultures. However, Schwartz and Rubel (2005) showed that across 70 countries, males attribute higher importance to self-enhancement and openness to change values than do females, while females attribute higher importance to selftranscendence values than males. While the previous crosscultural research on gender differences is not in total agreement, we propose:

H3a. Males attribute higher importance to openness to change values than do females.

H3b. Males attribute higher importance to self-enhancement values than do females.

H3c. Females attribute higher importance to conservation values than do males.

H3d. Females attribute higher importance to self-transcendence values than do males.

\section{Methods}

\subsection{Sample}

Our study consisted of 1057 managers/professionals from Australia $(n=153)$, Anglo-Canada $(n=256)$, New Zealand $(n=91)$,
South Africa $(n=132)$, the U.K. $(n=237)$, and the U.S. $(n=188)$. Participants responded to a mail survey conducted in 2002-2003 for Australia, Canada, South Africa, U.K., and U.S.A., and in 2009 for New Zealand. The average response rate was 23\%, with all countries exceeding $15 \%$, which is comparable to questionnaire survey response rates in international business research (Yang, Wang, \& Su, 2006). A cross-sectional sampling design was used to ensure consistency in data collection across the six countries. The goal of the data collection was to obtain country samples that were representative of the business population as a whole, rather than targeted samples of a specific sub-group (e.g., gender, race, industry) in the country. Furthermore, participants were removed from the sample if they were not nationals of their country and had not spent the majority of the first 15 years of their lives in their country. The demographics of the Anglo country samples are presented in Table 2.

\subsection{Instrument}

The SVS was used to measure individual values preferences (Schwartz, 1994). The survey was administered in English, since it is the official language or an official language in the sampled countries. The SVS instrument consists of 56 items measured with a 9-point Likert scale ranging from (-1) "opposed to my values" to (7) "of supreme importance." The cross-cultural equivalence for 45 of these items has been confirmed in extensive replicated studies across 63 countries (Schwartz, 1994; Schwartz \& Bardi, 2001). We used these 45 items to develop scores for the four higher-order values dimensions of openness to change, conservation, selfenhancement, and self-transcendence. Within-subject standardized scores were calculated to address potential cross-national differences in scale response style (cf Fischer, 2004). The country standardized means, standard deviations, and scale reliabilities (Cronbach $\alpha$ ) are presented in Table 3. For the total sample, the scale reliabilities were: openness to change $\alpha=.78$ (country range of $\alpha=.74$ to .80 ); self-enhancement $\alpha=.82$ (country range of $\alpha=.77$ to .83 ); conservation $\alpha=.84$ (country range of $\alpha=.79$ to .88 ); and self-transcendence $\alpha=.84$ (country range of $\alpha=.81$ to $.85)$.

\subsection{Analytic procedures}

A MANCOVA and post hoc group comparisons were conducted to test study hypotheses. The dependent variables in the MANCOVA were the four SVS dimensions (openness to change, conservation, self-enhancement, self-transcendence), and the independent variables were country, life-stage group (early adulthood, middle adulthood), and gender. To determine whether there were country differences in the influence of lifestage and gender on personal values orientations, we also included the country-by-life-stage and country-by-gender interactions. Given the country sample characteristic differences, education level, position level, company size, and industry were included as covariates. Post hoc group comparisons using the

Table 3

Personal values orientations: Standardized means, standard deviations, and scale reliabilities $(N=1057)$.

\begin{tabular}{|c|c|c|c|c|c|c|c|c|c|c|c|c|}
\hline & \multicolumn{3}{|c|}{ Openness to change } & \multicolumn{3}{|c|}{ Self-enhancement } & \multicolumn{3}{|c|}{ Conservation } & \multicolumn{3}{|c|}{ Self-transcendence } \\
\hline & Mean & (s.d.) & $\alpha$ & Mean & (s.d.) & $\alpha$ & Mean & (s.d.) & $\alpha$ & Mean & (s.d.) & $\alpha$ \\
\hline Australia & .11 & $(.42)$ & .80 & .00 & $(.37)$ & .83 & -.26 & $(.30)$ & .84 & .14 & $(.24)$ & .84 \\
\hline Canada & .08 & $(.43)$ & .76 & -.17 & $(.41)$ & .83 & -.18 & $(.31)$ & .84 & .20 & $(.25)$ & .84 \\
\hline New Zealand & .18 & $(.38)$ & .77 & -.25 & $(.43)$ & .83 & -.31 & $(.28)$ & .82 & .34 & $(.28)$ & .84 \\
\hline South Africa & -.02 & $(.45)$ & .79 & -.28 & $(.44)$ & .82 & -.08 & $(.36)$ & .88 & .17 & $(.28)$ & .85 \\
\hline U.K. & .12 & $(.40)$ & .78 & -.13 & $(.39)$ & .80 & -.27 & $(.33)$ & .82 & .25 & $(.28)$ & .85 \\
\hline U.S. & .10 & $(.40)$ & .74 & .03 & $(.38)$ & .77 & -.20 & $(.26)$ & .79 & .09 & $(.27)$ & .81 \\
\hline
\end{tabular}


Table 4

MANCOVA results: Influence of country and life-stage/gender on personal values orientations.

\begin{tabular}{|c|c|c|c|c|c|}
\hline & Openness to change & Self-enhancement & Conservation & Self-transcendence & Wilks' lambda $(F)$ \\
\hline & $F$ & $F$ & $F$ & $F$ & \\
\hline Country & $3.84^{* *}$ & $9.43^{* * *}$ & $9.42^{* * *}$ & $6.81^{* * *}$ & $.87\left(F=6.71^{* * *}\right)$ \\
\hline Life-stage & $13.63^{* * *}$ & $68.75^{* * *}$ & $13.34^{* * *}$ & $21.05^{* * *}$ & $.93\left(F=18.42^{* * *}\right)$ \\
\hline Gender & $4.31^{*}$ & $26.72^{* * *}$ & 2.77 & $13.59^{* * *}$ & $.93\left(F=17.30^{* * *}\right)$ \\
\hline Country $\times$ Life-stage & .23 & 1.68 & 1.58 & $1.96^{+}$ & $.97(F=1.39)$ \\
\hline Country $\times$ Gender & 1.13 & .73 & $2.07^{+}$ & .77 & $.97(F=1.35)$ \\
\hline Education & $13.40^{* * *}$ & 1.18 & $29.89^{* * *}$ & $4.03^{*}$ & $.95\left(F=11.37^{* * *}\right)$ \\
\hline Position level & $5.82^{*}$ & $19.78^{* * *}$ & $3.59^{+}$ & $11.87^{* * *}$ & $.97\left(F=5.83^{* * *}\right)$ \\
\hline Company size & $5.18^{*}$ & 1.56 & 2.60 & .27 & $.99(F=1.49)$ \\
\hline Industry & 1.22 & 1.15 & .19 & $3.59^{* *}$ & $.97(F=1.44)$ \\
\hline
\end{tabular}

$+p<.10$

${ }^{*} p<.05$.

$p<.01$.

${ }^{* * *} p<.001$.

Least Significant Difference test were conducted for significant effects. To identify the nature of the cultural values profile for each country, paired-sample $t$-tests using the four SVS dimensions (after adjusting for the influence of covariates) were conducted.

\section{Results}

As reported in Table 4, the MANCOVA showed significant effects for country (Wilks $\lambda=.87, F=6.71, p<.001$ ), life-stage (Wilks $\lambda=.93, F=18.42, p<.001$ ), and gender (Wilks $\lambda=.93, F=17.33$, $p<.001$ ). The country-by-life-stage (Wilks $\lambda=.97, F=1.39$ ) and the country-by-gender (Wilks $\lambda=.97, F=1.35$ ) interactions were not significant overall. In addition, there were significant effects for the covariates of education (Wilks $\lambda=.95, F=11.37, p<.001$ ) and position level (Wilks $\lambda=.97, F=5.83, p<.001$ ).

\subsection{Country and values orientations}

Hypothesis 1 proposed that there would be significant differences in values orientations among the Anglo countries. Specifically, Hypotheses 1a to 1d proposed country differences in values orientations such that South African participants would attribute lower importance to openness to change (H1a) and self-enhancement (H1b) values and higher importance to conservation (H1c) and self-transcendence (H1d) values than would participants in other Anglo countries (Australia, Canada, New Zealand, U.K., U.S.).

The data in Table 5 indicates that there were significant country differences for all four values: openness to change $(F=3.84$, $p<.01)$, self-enhancement $(F=9.43, \quad p<.001)$, conservation $(F=9.42, p<.001)$, and self-transcendence $(F=6.81, p<.001)$. Table 5 presents the results of the post hoc analyses of country differences. As proposed, South African participants attributed

Table 5

Multiple comparison test findings for country differences for the four values dimensions. ${ }^{\text {a }}$

\begin{tabular}{|c|c|c|c|c|c|}
\hline \multicolumn{6}{|c|}{ Openness to change } \\
\hline \multicolumn{6}{|c|}{ New Zealand } \\
\hline \multicolumn{6}{|l|}{ U.K. } \\
\hline \multicolumn{6}{|l|}{ Australia } \\
\hline \multicolumn{6}{|l|}{ U.S. } \\
\hline Canada & ${ }^{*}$ & & & & \\
\hline \multirow{2}{*}{ South Africa } & $*$ & * & * & * & * \\
\hline & New Zealand & U.K. & Australia & U.S. & Canada \\
\hline \multicolumn{6}{|c|}{ Self-enhancement } \\
\hline \multicolumn{6}{|l|}{ U.S. } \\
\hline \multicolumn{6}{|l|}{ Australia } \\
\hline U.K. & $*$ & $*$ & & & \\
\hline Canada & $*$ & $*$ & & & \\
\hline New Zealand & $*$ & * & * & & \\
\hline \multirow[t]{2}{*}{ South Africa } & $*$ & $*$ & * & $*$ & \\
\hline & U.S. & Australia & U.K. & Canada & New Zealand \\
\hline \multicolumn{6}{|l|}{ Conservation } \\
\hline \multicolumn{6}{|l|}{ South Africa } \\
\hline Canada & ${ }^{*}$ & & & & \\
\hline U.S. & $*$ & & & & \\
\hline Australia & ${ }^{*}$ & $*$ & & & \\
\hline U.K. & * & $*$ & * & & \\
\hline \multirow[t]{2}{*}{ New Zealand } & ${ }^{*}$ & * & * & & \\
\hline & South Africa & Canada & U.S. & Australia & U.K. \\
\hline \multicolumn{6}{|c|}{ Self-transcendence } \\
\hline \multicolumn{6}{|c|}{ New Zealand } \\
\hline U.K. & ${ }^{*}$ & & & & \\
\hline Canada & $*$ & * & & & \\
\hline South Africa & ${ }^{*}$ & ${ }^{*}$ & & & \\
\hline Australia & ${ }^{*}$ & $*$ & * & & \\
\hline \multirow[t]{2}{*}{ U.S. } & ${ }^{*}$ & $*$ & * & $*$ & \\
\hline & New Zealand & U.K. & Canada & South Africa & Australia \\
\hline
\end{tabular}

a Group differences $(p<.05$ level) based on Least Significant Difference post hoc analyses. 
lower importance to openness to change and conservation values than participants in the five other Anglo countries. South African participants also attributed lower importance to self-enhancement values than participants in Australia, Canada, U.K., and U.S., with no significant difference with New Zealand participants. In respect to self-transcendence values, South African participants attributed higher importance to self-transcendence than did U.S. participants, but had lower self-transcendence scores than New Zealand and U.K participants. In sum, Hypotheses $1 \mathrm{a}$ and $1 \mathrm{c}$ were fully supported, Hypothesis $1 \mathrm{~b}$ was moderately supported, and Hypothesis $1 \mathrm{~d}$ was not supported.

The post hoc analyses also identified several interesting values differences among the five countries that were expected to be similar based on economic development level and common historic and political roots. With respect to openness to change values, New Zealand participants had significantly higher scores than Canadian participants. With respect to self-enhancement values, U.S. and Australian participants had higher scores than U.K., Canada, and New Zealand participants, and the U.K. participants scored higher than New Zealand participants. With respect to conservation values, Canadian and U.S. participants had higher scores than U.K. and New Zealand participants, and Canadian participants had higher scores than Australian participants. In regards to self-transcendence values, New Zealand participants had higher scores than U.K. participants who had higher scores than participants in Canada, Australia, and the U.S. Furthermore, Canadian participants had higher self-transcendence values scores than Australian participants. Thus, in support of Hypothesis 1, we found substantial evidence of values heterogeneity among the countries of the former Anglo cluster.

\subsection{Life-stage and values orientations}

Hypothesis 2 proposed that early adulthood participants would attribute higher importance to openness to change (H2a) and selfenhancement ( $\mathrm{H} 2 \mathrm{~b})$ values than middle adulthood participants, who in turn would attribute higher importance to conservation (H2c) and self-transcendence (H2d) values than their younger counterparts. Consistent with Hypothesis 2, early adulthood participants had higher openness to change $(F=13.63, p<.001)$ and self-enhancement $(F=68.75, p<.001)$ scores than middle adulthood participants; and middle adulthood participants had higher conservation $(F=13.34, p<.001)$ and self-transcendence $(F=21.05, p<.001)$ scores than early adulthood participants. The only post hoc analysis inconsistency with the overall findings was no significant life-stage difference in self-transcendence for Australian participants. Thus, Hypothesis 2 was fully supported with respect to life-stage differences for openness to change, selfenhancement, and conservation values, and strongly supported (five of six countries) for self-transcendence values.

\subsection{Gender and values orientations}

Hypothesis 3 proposed that male participants would attribute higher importance to openness to change (H3a) and selfenhancement (H3b) values, whereas female participants would attribute higher importance to conservation (H3c) and selftranscendence (H3d) values. Consistent with Hypothesis 3, male participants had higher openness to change $(F=4.31, p<.05)$ and self-enhancement $(F=26.72, p<.001)$ scores than female participants who in turn, had higher self-transcendence $(F=13.59$, $p<.001)$ scores than male participants. Inconsistent with $\mathrm{Hy}-$ pothesis 3 , there was no significant gender difference in the importance of conservation values $(F=2.77)$. The country-level post hoc analyses identified only one inconsistency with the overall findings. For conservation, male participants attributed higher importance than female participants in Australia and the U.S., whereas there were no significant gender differences in conservation values for participants in Canada, New Zealand, South Africa, and the U.K. Thus, Hypothesis 3 was fully supported with respect to gender differences for openness to change, selfenhancement, and self-transcendence values, with mixed support found for conservation values.

\subsection{Cultural values profiles}

We also determined the cultural values profiles for each country in terms of differences in the relative importance accorded to each value (at the $p<.05$ level) after controlling for the covariates. Australia, New Zealand, the U.K., and the U.S. had the following values profile: self-transcendence $>$ openness to change $>$ self-enhancement $>$ conservation. For Canada, the values profile was: self-transcendence $>$ openness to change $>$ (selfenhancement, conservation). And for South Africa, the values profile was: self- transcendence $>$ openness to change $>$ conservation $>$ self-enhancement.

\subsection{Results for the covariates}

The MANCOVA showed that education level was positively related to the importance attributed to openness to change $(F=13.40, p<.001)$, and negatively related to conservation $(F=29.89, p<.001)$ and self-transcendence $(F=4.03, p<.05)$. Position level was positively related to openness to change $(F=5.82, p<.05)$, self-enhancement $(F=19.78, p<.001)$, and self-transcendence $(F=11.87, p<.001)$, but negatively related to conservation $(F=3.59, p<.10)$. Participants in larger companies attributed higher importance to openness to change $(F=5.18$, $p<.05)$, and participants in manufacturing and services industries attributed lower importance to self-transcendence $(F=3.59$, $p<.01$ ) than those in other industry sectors.

\section{Discussion and conclusions}

We began this study by asking two questions. One, are the Anglo countries still a values-cluster? Two, does investigating micro-level factors assist in understanding values orientations across the Anglo countries? This study addresses these questions in a number of respects.

\subsection{Similarities and differences among the Anglo cluster countries}

We begin our summary review of values similarities and differences with a focus on the country cultural values profiles (see Table 6). One noteworthy similarity across all six countries is that self-transcendence values are ranked as the most important value with openness to change ranked as the second most important value. Lower rankings are accorded to self-enhancement and conservation values. Self-transcendence values are associated with the post-materialistic concern for the welfare of others and interpersonal trust, whereas self-enhancement values are associated with the pursuit of self-interested materialistic and survival needs (Schwartz, 2006). The high emphasis on self-transcendence across these six countries with high polity ratings (Marshall et al., 2010) is consistent with previous research that has found a high emphasis on self-transcendence values is associated with societal democratization and pro-social behavior (Schwartz, 2007). In that participants in all six countries viewed self-transcendence values as relatively more important than self-enhancement values. Our findings differ from those of Ashkanasy et al. (2002) who concluded that the Anglo cultural values profile places a greater emphasis on individual materialistic goals and interests than on 
Table 6

Number of societal dyad differences and country cultural values profiles. ${ }^{\text {a }}$

\begin{tabular}{|c|c|c|c|c|c|c|}
\hline & Australia & Canada & New Zealand & South Africa & U.K. & U.S. \\
\hline Australia & (10) & $\begin{array}{l}3 \text { (self-enhancement, } \\
\text { conservation, } \\
\text { self-transcendence) }\end{array}$ & $\begin{array}{l}2 \text { (self-enhancement, } \\
\text { self-transcendence) }\end{array}$ & $\begin{array}{l}3 \text { (openness to change, } \\
\text { self-enhancement, } \\
\text { conservation) }\end{array}$ & $\begin{array}{l}2 \text { (self-enhancement, } \\
\text { self-transcendence) }\end{array}$ & 0 \\
\hline Canada & & (13) & $\begin{array}{l}3 \text { (openness to change, } \\
\text { conservation, } \\
\text { self-transcendence) }\end{array}$ & $\begin{array}{l}3 \text { (openness to change, } \\
\text { self-enhancement, } \\
\text { conservation) }\end{array}$ & $\begin{array}{l}2 \text { (conservation, } \\
\text { self-transcendence) }\end{array}$ & $\begin{array}{l}2 \text { (self-enhancement, } \\
\text { self-transcendence) }\end{array}$ \\
\hline New Zealand & & & (13) & $\begin{array}{l}3 \text { (openness to change, } \\
\text { conservation, } \\
\text { self-transcendence) }\end{array}$ & $\begin{array}{l}2 \text { (self-enhancement, } \\
\text { self-transcendence) }\end{array}$ & $\begin{array}{l}3 \text { (self-enhancement, } \\
\text { conservation, } \\
\text { self-transcendence) }\end{array}$ \\
\hline South Africa & & & & (17) & $\begin{array}{l}4 \text { (openness to change, } \\
\text { self-enhancement, } \\
\text { conservation, } \\
\text { self-transcendence) }\end{array}$ & $\begin{array}{l}4 \text { (openness to change, } \\
\text { self-enhancement, } \\
\text { conservation, } \\
\text { self-transcendence) }\end{array}$ \\
\hline U.K. & & & & & (13) & $\begin{array}{l}3 \text { (self-enhancement, } \\
\text { conservation, } \\
\text { self-transcendence) } \\
\text { (12) }\end{array}$ \\
\hline $\begin{array}{r}\text { Cultural } \\
\text { values } \\
\text { profile }\end{array}$ & $\begin{array}{l}\text { Self-transcendence } \\
>\text { openness to change } \\
>\text { self-enhancement } \\
>\text { conservation }\end{array}$ & $\begin{array}{l}\text { Self-transcendence } \\
>\text { openness to change } \\
>\text { (self-enhancement, } \\
\text { conservation) }\end{array}$ & $\begin{array}{l}\text { Self-transcendence } \\
>\text { openness to change } \\
>\text { self-enhancement } \\
>\text { conservation }\end{array}$ & $\begin{array}{l}\text { Self-transcendence } \\
>\text { openness to change } \\
>\text { conservation } \\
>\text { self-enhancement }\end{array}$ & $\begin{array}{l}\text { Self-transcendence } \\
>\text { openness to change } \\
>\text { self-enhancement } \\
>\text { conservation }\end{array}$ & $\begin{array}{l}\text { Self-transcendence } \\
>\text { openness to change } \\
>\text { self-enhancement } \\
>\text { conservation }\end{array}$ \\
\hline
\end{tabular}

a Total number of societal dyad differences for each country is in parentheses on the diagonal. Note: S. Africa differences shaded, as an example.

collective interests. Even so, our finding that openness to change values are consistently rated as more important than conservation values is somewhat consistent with Ashkanasy et al.'s (2002) characterization of Anglo cluster values as having a high future orientation and moderate uncertainty avoidance values.

Despite these overall profile similarities, we found significant differences within the Anglo cluster with respect to the importance accorded to all four values (see Table 6). As expected, because of its less developed political and economic systems, South Africa exhibits a different values profile from the other countries with the highest number of significant dyadic values differences ( 17 out of a total of 20). Compared to the other five countries, South African participants attributed significantly higher importance to conservation values and lower importance to openness to change values and with one exception, significantly lower importance to selfenhancement values. Although the South Africa culture values profile was similar in respect to the highest importance accorded to self-transcendence values and then to openness to change values, one unique aspect was that conservation values were viewed as significantly more important than self-enhancement values. We note that for a sample of white South Africans who represent a small minority of the South African population, Ashkanasy et al. (2002) identified that South Africa has a distinct cultural values profile with much higher uncertainty avoidance values. In sum, our findings provide further evidence that postapartheid South Africa should no longer be considered an Anglo cluster country (e.g., Inglehart \& Welzel, 2005; Schwartz, 2006).

For the remaining five Anglo countries, one important finding relates to no significant values differences between Australia and the U.S. Participants in these two countries were more selfenhancing and less self-transcendent than their counterparts in Canada, New Zealand, and the U.K. Whereas the U.S. has often been identified as being somewhat culturally and politically distinct from other Anglo countries (e.g., Inglehart \& Welzel, 2005; Schwartz, 2006; Shafer, 1999), recent events may have exacerbated these differences. The U.S. has been experiencing difficult times with evidence of eroding trust with political establishments, inequality in education, rising economic imbalances, declining civil/social capital, growing military presence in Afghanistan and Iraq, and increased concerns with international terrorism and domestic safety (Andersen, Curtis, \& Grabb, 2006; Putnam, 2000;
Wolnicki, 2009). Such economic distress, along with social and physical insecurity, can lead to a cultural shift focusing more upon survival values (Inglehart, 1997). Our findings also suggest that the enduring American values of independence, achievement, and personal power, which form the very core of U.S. culture, (Kitayama, Conway, Petromonaco, Park, \& Plaut, 2010) may also be characteristic of Australian culture. For instance, the past three decades has seen a neoliberal shift in Australian economic and social public policies towards free market principles and deregulation similar to those in the U.S. (Western et al., 2007). Cultural support for these changes would be indicated by Schwartz's (2006) finding that a self-enhancement values orientation is associated with support for centre-right political ideology. Another factor that indicates a cultural values difference between Australia and the other Commonwealth member countries in this study is that Australia has had an active Republicanism movement to replace the current constitutional monarchy form of government. While the 1999 Australian Republic Referendum was defeated (55\% voted no), there remains significantly more support for formal separation from the U.K. monarchy than in Canada and New Zealand (Ritchie \& Markwell, 2006).

In contrast, New Zealanders were the most self-transcendent, and although similar to Canada, the least self-enhancing of these five Anglo countries. Inglehart (1997) argued that prolonged periods of peace and prosperity in a society has the effect of satisfying lower order needs of individuals to allow for the satisfaction of higher order self-esteem and self-actualization needs that engender post-materialistic values of egalitarianism, interpersonal trust, tolerance for diversity, and self-transcendence. This explanation fits New Zealand, which has enjoyed a high degree of social and political stability and a modern welfare system for the past few decades (New Zealand Government, 2010). In 2009, New Zealand was ranked the second least politically risky country in the world (IMD, 2009). Its economy also experienced the longest sustained period of growth in three decades during the years from 1999 to 2008, including a robust labor market (New Zealand Government, 2010).

Although U.K. participants attributed lower importance to selftranscendence values and higher importance to self-enhancement values than did New Zealand participants, we found that both countries had similar types of values differences with Australia and 
the U.S. Whereas New Zealand and U.K. values differences with Australia were limited to having higher self-transcendence and lower self-enhancement values, they also attributed significantly lower importance to conservation values than U.S. participants. Relative to Canada, both New Zealand and U.K. participants attributed lower importance to conservation values and higher importance to self-transcendence, however there was an additional values difference for New Zealand participants who attributed higher importance to openness to change values. Thus, with this one exception, New Zealand and U.K. appear to denote a very similar configuration of values within this set of Anglo countries.

Canada emerges as a different country that projects a distinct values system derived from being both a next-door neighbor of the U.S. and an adherent to British traditions. This is suggested by crossvergence theory (Ralston, Holt, Terpstra, \& Yu, 2008). Unlike the other four Anglo countries, Canadian respondents rated conservation values to be of similar importance to self-enhancement values. Other research has shown that Canadians are more conservative than other advanced industrial democracies (Inglehart, Basanez, Diez-Medrano, Halman, \& Luijkx, 2004; National Post, 2005). Our findings indicate that Canada is at a similar level to that of the U.S. Canadians are also self-reliant and skeptical of letting organizations become too powerful, but are in favor of competition and achievement (less than the U.S.), concerned about social inequities and strong supporters of social safety nets for all (National Opinion Poll, 2006). In this regard, we found that Canada respondents were in a middle position being more self-transcendent and less self-enhancing than Australian and U.S. respondents but being less self-transcendent and being similarly (low) selfenhancing as New Zealand and U.K. respondents.

In sum, this study's findings of differences in values orientations indicate current-day heterogeneity across the Anglo countries. Assuming that previous studies that identified the Anglo cluster were accurate, and subscribing to the perspective that values are likely to change over a period of time (Bardi, Lee, HofmannTowfigh, \& Soutar, 2009; Rokeach, 1973; Schwartz \& Rubel, 2005), this study has identified a complex pattern of values variation across Anglo countries. This finding is in direct contrast to previous research that reported values convergence across Anglo countries, which argued that the Anglo cluster is a modern legacy of the vast power of the British Empire (Ashkanasy et al., 2002; Ronen \& Shenkar, 1985). A possible explanation of this values heterogeneity is that rapid globalization and technological advancements over the past two decades may have influenced these societies to evolve in differing ways with respect to their personal values systems. In this context, our current findings revise rather than refute those of previous studies.

\subsection{Contribution of micro-level influences to understanding values orientations}

As identified by Steel and Taras (2010), we found that despite societal-level similarities in economic development level and polity, micro-level influences or individual characteristics (lifestage and gender) play an important role in influencing personal values orientations. Consistent with life-stage theory (Erikson, 1997), people in early adulthood were more open to change and self-enhancing but less conservative and self-transcendent than people in middle adulthood. This indicates that as people grow older, they tend to become more embedded in social networks and committed to habitual patterns. Older people are less likely to respond to new challenges (Schwartz, Melech, Lehmann, Burgess, \& Harris, 2001). With respect to the influence of gender, we found that males attributed higher importance to self-enhancement and openness to change, while females attributed higher importance to self-transcendence values. These findings partially support previous research by Schwartz and Rubel (2005), but contradict Struch et al. (2002) who argue that females have the same values orientations as males. For conservation values, our findings are contrary to those of Schwartz and Rubel (2005) who found that females attributed higher importance to conservative values than males. One explanation for not finding significant differences between males and females could be the different nature of study participants. Schwartz and Rubel (2005) had a general population sample whereas our sample consisted of business managers and professionals. Globalization may be advancing a more common "global business culture" that affects individuals across the economic development continuum. Thus, businesspeople (both male and female) may be more similar to each other than to the general populations of their countries due to the homogenizing influence of a global business culture that encourages them to be less conservative.

In summary, working from the assumption that these Anglo countries could legitimately have been described as a cluster a quarter century or more ago (Ronen \& Shenkar, 1985), we believe that what we may be seeing is deviating-crossvergence (Ralston, 2008). Simply stated, deviating-crossvergence is: countries becoming less alike due to differing sets of external economic and/or political influences being placed upon them over time. While seeing these Anglo countries become different is part of the answer, what is intriguing is the consistent pattern of micro-level influences across these countries. A question this raises is: are these micro-level patterns of personal values universal beyond the Anglo cluster? Although our study data cannot address this question, Steel and Taras (2010) found that significant crosscultural variance in values is explained by individual characteristics such as age, education, and gender. The consistency of microlevel influences in this study also supports the relevance of investigating these factors. We raise this as an issue for consideration because it emphasizes the complexity of understanding behavior cross-culturally and points to the fact that collectively, to date, we have merely scratched the surface in this area and that we need to develop more encompassing and complex cultural models of behavior.

\subsection{Limitations}

This research has limitations that we wish to acknowledge. First, our data is cross-sectional, and was not able to capture the evolving nature of values transitions. Second, this study used the Schwartz Values Survey whereas the majority of studies which have identified an Anglo cluster of countries used different cultural values typologies and measures, primarily that of or based upon Hofstede (1980). Hence, there is the question about the comparability of values data (and findings) to other Anglo cluster studies. Third, our sample consisted of managers and professionals. While relevant for business research and for developing international management theories, we must be cautious in generalizing these findings to general population samples. Finally, although we argued that culture is not static, we treated culture as an independent variable in the analyses. This was also done in the previous Anglo cluster studies (e.g., Ashkanasy et al., 2002; Hofstede, 2001).

\subsection{Managerial relevance}

For managers to perform successfully in the global economy, knowledge about societal values is crucial given that values precede behavior. Understanding values helps in planning for business entry, growth, marketing as well as management of human resources. The fast pace of globalization along with the 
merging of economic philosophies, the Internet revolution, and technological advancements, are guiding societies towards the development of new configurations of cultural values. Therefore, one key implication for practitioners concerns the need to reevaluate the notion of country clusters. In particular, our findings indicate that the Anglo cluster concept appears to be no longer helpful in categorizing the cultural values of businesspersons in these countries. What may be helpful is a heightened awareness of the influence of individual (micro-level) factors on cultural values. Thus, rather than just focusing on country differences, managers should also be sensitive to interpersonal values differences residing within countries.

As globalization has proceeded, it has created many changes that influence all of us. Another managerial implication is that values/behavior evolution is both inevitable and dynamic. The outcomes are often complex and paradoxical in nature as our study reveals. In reality, these paradoxes are helpful and frequently essential for understanding and highlighting the changes that are occurring because of globalization. Managers need to be cognizant of the complexity underlying these changes in order to minimize inaccurate generalizations as well as to develop in-depth country analyses (Gannon, 2008).

\subsection{Contribution and future directions for research}

Our study contributes to the international management literature in at least three ways. First, this study found values differences among the Anglo countries, implying that there may have been longitudinal values change across the Anglo countries. Second, we found that micro-level factors (life-stage and gender) contributed to understanding the nuances of within-societal differences across the Anglo countries. Third, our findings suggest that future research in this area must be designed with caution, and incorporate micro-level influences for a complete analysis. An 'either/or' approach (i.e., micro or macro factors) to capture a country values profile does not appear to be sufficient.

Such a complex pattern of values systems among the Anglo countries leads us to ask a set of important questions for future research: Why do some countries show greater evidence of values transition than others? What aspects or factors determine change in personal values? In particular, why do some countries attribute higher importance to a value more than other countries, despite having fairly similar levels of economic development, a British legacy, and stable political systems? These questions are difficult to answer due to the unique nature of socio-economic and political events in each of the Anglo countries (Ralston, 2008; Tan, 2002). Our findings highlight the need for more in-depth and integrative analyses of values transitions provided by qualitative analyses.

In conclusion, across the former Anglo cluster we observed deviating-crossvergence. Among the countries of the Anglo cluster we see a fragmentation of the cluster. In essence, the U.S. and Australia have values convergence. To a lesser degree, we identified important values similarities between New Zealand and the U.K. We found Canada to be a country that is an apparent example of values crossvergence (Ralston et al., 2008), whereby it exhibits unique values influenced by both a powerful neighbor to the south as well as allegiance to Queen and country. In addition, South Africa is the true outlier fragment of this set of countries, it is the one that has gone through the most radical social change over the past three decades. Remembering that our sample design was to be representative of the businesspeople of a country, our South Africa sample includes all ethnic/racial groups that would be subsumed within today's population of businesspeople, as is true of the other country samples. Thus, if the demographics of the business populations have changed in any or all of these countries, so be it. The question as to whether these countries are a cluster today remains a valid one. Clearly, our $21^{\text {st }}$ century data findings dispute the notion that the former Anglo cluster exists today.

\section{References}

Andersen, R., Curtis, J., \& Grabb, E. (2006). Trends in civic association in four democracies: The special case of women in United States. American Sociological Review, 71: 376-400.

Ashkanasy, N. M., Trevor-Roberts, E., \& Earnshaw, L. (2002). The Anglo cluster: Legacy of the British Empire. Journal of World Business, 37: 28-39.

Au, K., \& Cheung, M. W. L. (2004). Intra-cultural variation and job autonomy in 42 countries. Organization Studies, 25(8): 1339-1362.

Bardi, A., Lee, J. A., Hofmann-Towfigh, N., \& Soutar, G. (2009). The structure of intraindividual value change. Journal of Personality and Social Psychology, 97: 913-929.

Costa, P. T., Terracciano, A., \& McCrae, R. R. (2001). Gender differences in personality traits across cultures: Robust and surprising findings. Journal of Personality and Social Psychology, 81: 322-331.

Davis, H. J., Chatterjee, S. R., \& Heuer, M. (2006). Management in India: Trends and transition. New Delhi: Sage.

Eagly, A. H. (1995). Science and the politics of comparing men and women. American Psychologist, 50: 145-158.

Egri, C. P., \& Ralston, D. A. (2004). Generation cohorts and personal values: A comparison of China and the United States. Organization Science, 15: 210-220.

Erikson, E. (1997). The life cycle completed. New York: Norton.

Fischer, R. (2004). Standardization to account for cross-cultural response bias: A classification of score adjustment procedures and review of research in JCCP. Journal of Cross-Cultural Psychology, 35: 263-282.

Gannon, M. J. (2008). Paradoxes of culture and globalization. London: Sage.

Hofstede, G. (1980). Culture's consequences: International differences in workrelated values. Newbury Park, CA: Sage.

Hofstede, G. (2001). Culture's consequences: Comparing values, behaviours, institutions, and organizations across nations (2nd ed.). Thousand Oaks, CA: Sage.

House, R. J., Hanges, P. J., Javidan, M., Dorfman, P. W., \& Gupta, V. GLOBE Associates. (2004). Leadership, culture, and organizations: The GLOBE study of 62 societies. Thousand Oaks, CA: Sage.

IMD. (2009). IMD World Competiveness Yearbook. Accessed March 2010. Available online at http://www.imd.ch/research/publications/wcy/index.cfm.

Inglehart, R. (1997). Modernization and postmodernization: Cultural, economic, and political change in 43 societies. Princeton, NJ: Princeton University Press.

Inglehart, R., Basanez, M., Diez-Medrano, J., Halman, L., \& Luijkx, R. (2004). Human beliefs and values: A cross cultural sourcebook based on the 1999-2002 values surveys. Cuidad de Mexico: Siglo XX1 Editores.

Inglehart, R., \& Welzel, C. (2005). Modernization, cultural change, and democracy: The human development sequence. New York: Cambridge University Press.

Khilji, S. E. (2004). Wither tradition: An evidence of generational differences in human resource satisfaction from Pakistan. International Journal of Cross Cultural Management, 4(2): 141-156.

Kitayama, S., Conway, L. G., III, Pietromonaco, P. R., Park, H., \& Plaut, V. C. (2010). Ethos of independence across regions in the United States: The production-adoption model of cultural change. American Psychologist, 65: 559-574.

Kwong, J. (1994). Ideological crisis among China's youths: Values and official ideology. The British Journal of Sociology, 45: 247-285.

LaFontaine, J. S. (1978). Sex and age as principles of social differentiation. New York: Academic Press.

Levinson, D. J. (1997). The seasons of a woman's life. New York: Ballentine.

Lyons, S., Duxbury, L., \& Higgins, C. (2005). Are gender differences in basic human values a generational phenomenon? Sex Roles, 53: 763-778.

Marshall, M. G., Jaggers, K., Gurr, T. R. (2010). Polity IV project: Political regime characteristics and transitions, 1800-2003. Available at: http://www.systemicpeace.org/polity/ polity4.htm.

McCrae, R. R. (2002). NEO-PI-R data from 36 cultures: Further intercultural comparison. In R. R. McCrae \& J. Allik (Eds.), The five-factor model of personality across cultures (pp. 105-125). New York: Kluwer Academics.

McCrae, R. R., \& Terracciano, A. 78 Members of the Personality Profiles of Culture Project. (2005). Universal features of personality traits fro observer's perspective: Data from 50 cultures. Journal of Personality and Social Psychology, 88: 547-561.

National Post. (2005). The Canadian Values Survey: A joint project of Innovative Research Group, the Dominion Institute and the National Post. Day Five Release. Available at http://www.innovativeresearch.ca/Canadian\%20Values\%20Study_Factum\%20280905.pdf.

New Zealand Government. (2010). New Zealand: Economic and Financial Review 2009. Available at http://www.nzdmo.govt.nz/publications/nzefo/2009/nzefo-09.pdf.

Putnam, R. D. (2000). Bowling alone: America's declining social capital. New York: Simon and Schuster.

Ralston, D. A. (2008). The crossvergence perspective: Reflections and projections. Journal of International Business Studies, 39: 27-40.

Ralston, D. A., Egri, C. P., Casado, T., Fu, P. P., \& Wagenheim, F. (2009). The impact of life stage and societal culture on subordinate influence ethics: A study of Brazil, China, Germany, and the U.S.. Journal of International Management, 15: 374-386.

Ralston, D. A., Hallinger, P., Egri, C. P., \& Naothinsuhk, S. (2005). The effects of culture and life stage on workplace strategies of upward influence: A comparison of Thailand and the United States. Journal of World Business, 30: 321-337.

Ralston, D. A., Holt, D. A., Terpstra, R. H., \& Yu, K. C. (2008). The impact of national culture and economic ideology on managerial work values: A study of the United States, Russia, Japan, and China. Journal of International Business Studies, 39: 8-26. 
Ritchie, J., \& Markwell, D. (2006). Australian and commonwealth republicanism. The Round Table, 95(387): 727-737.

Rokeach, M. (1973). The nature of human values. New York: The Free Press.

Ronen, S., \& Shenkar, O. (1985). Clustering countries on attitudinal dimensions: A review and synthesis. Academy of Management Review, 10: 435-454

Sawyerr, O. O., Strauss, J., \& Yan, J. (2005). Individual value structure and diversity attitudes: The moderating effects of age, gender, race, and religiosity. Journal of Managerial Psychology, 20: 498-521.

Schmitt, M.J. (2008). Why can't a man be more like a woman? Sex differences in big five personality traits across 55 cultures. Journal of Personality and Social Psychology, 94: $162-182$.

Schwartz, S. H. (1994). Cultural dimensions of values: Towards an understanding of national differences. In U. Kim, H. C. Triandis, C. Kagitcibasi, S. C. Choi, \& G. Yoon (Eds.), Individualism and collectivism: Theoretical and methodological issues (pp. 85119). Thousand Oaks, CA: Sage.

Schwartz, S. H. (2006). A theory of cultural value orientations: Explication and applications. Comparative Sociology, 5(2/3): 137-182.

Schwartz, S. H. (2007). Universalism values and the inclusiveness of our moral universe. Journal of Cross-Cultural Psychology, 38: 711-728.

Schwartz, S. H., \& Bardi, A. (2001). Value hierarchies across cultures: Taking a similarities perspective. Journal of Cross Cultural Psychology, 32: 268-290.

Schwartz, S. H., Melech, G., Lehmann, A., Burgess, S., \& Harris, M. (2001). Extending the cross-cultural validity of the theory of basic human values with a different method of measurement. Journal of Cross Cultural Psychology, 32: 519-542.

Schwartz, S. H., \& Rubel, T. (2005). Sex differences in value priorities: Cross-cultural and multimethod studies. Journal of Personality and Social Psychology, 86: 560584.

Setterson, R. A., Jr., \& Mayer, K. U. (1997). The measure of age, age structuring, and the life course. Annual Review of Sociology, 23: 233-261.
Shafer, B. E. (1999). American exceptionalism. Annual Review of Political Science, 2: $445-$ 463.

Smith, P. B., \& Schwartz, S. H. (1997). Values. In C. Kagitcibasi \& M. H. Segall (Eds.), Handbook of cross-cultural psychology. Boston: Allyn and Bacon.

Steel, P., \& Taras, V. (2010). Culture as a consequence: A multi-level multivariate metaanalysis of the effects of individual and country characteristics on work-related cultural values. Journal of International Management, 16: 211-233.

Struch, N., Schwartz, S. H., \& Van der Kloot, W. A. (2002). Meanings of basic values for women and men: A cross-cultural analysis. Personality and Social Psychology Bulletin, 28(1): 16-28.

Tan, B. L. B. (2002). Researching managerial values: A cross-cultural comparison Journal of Business Research, 55: 815-821.

Tung, R. L., \& Verbeke, A. (2010). Beyond Hofstede and GLOBE: Improving the quality of cross-cultural research. Journal of International Business Studies, 41 $1259-1274$.

Warner, M. (2004). Human resource management in China revisited: Introduction. The International Journal of Human Resource Management, 15: 617-634.

Western, M., Baxter, J., Pakulski, J., Tranter, B., Western, J., van Egmond, M., Chesters, J. Hosking, A., O’Flaherty, M., \& van Gellecum, Y. (2007). Neoliberalism, inequality and politics: The changing face of Australia. Australian Journal of Social Issues, 42(3): 401-418.

Wolf, E. R. (1966). Kinship, friendship, and patron-client relations in complex societies. In M. Banton (Ed.), The social anthropology of complex societies (pp. 1-22). New York: Frederick A. Praeger.

Wolnicki, M. (2009). The post-conservative orphan: Why the U.S. needs an effective economic government policy. International Journal of Social Economics, 36(1/2): 5-

Yang, Z., Wang, X., \& Su, C. (2006). A review of research methodologies in international business. International Business Review, 15: 601-617. 